\title{
Research on Teaching Design and Application of Flipped Classroom Mode
}

\author{
Zhenhui Wang \\ Ankang University, Ankang, 725000, China
}

Keywords: Flipped Classroom; Teaching design; Personalized teaching

\begin{abstract}
Flipped Classroom mode is a new teaching mode, which not only reflects 'student-centered' teaching concept but also changes traditional teaching structure and process, drives bold innovation of teaching methods and learning approaches and is of great significance for realization of personalized teaching. This thesis starts with introducing source of the Flipped Classroom mode and studies teaching design and application of the Flipped Classroom mode.

The Flipped Classroom is also called 'inverted classroom' and 'reverse classroom', which is a new teaching mode where roles of teachers and students in traditional teaching are changed and classroom time is re-planned by arranging knowledge instruction and knowledge internalization reversely. In the Flipped Classroom mode, students need finish learning knowledge at home by themselves and classroom is the site where teacher-student and student-student interactions are implemented. Being affected by many factors, China has not popularized the Flipped Classroom mode but only practiced and tried it at several schools of pilot teaching reform up to now. Therefore, it is essential to enhance cognition and comprehension about the Flipped Classroom and rethink about whether domestic education needs the Flipped Classroom or not in order to construct localized development paths of the Flipped Classroom teaching mode.
\end{abstract}

\section{Source of the Flipped Classroom mode}

It was in the early $19^{\text {th }}$ century that the Flipped Classroom thought appeared. In detail, The United States Military Academy at West Point created a set of teaching methods, i.e., students utilized sources provided by their teachers to learn before class, while classroom time was used for group cooperation to solve problems jointly. This teaching method reflected by basic concept of the Flipped Classroom. In 2000, Americans Glenn Platt and Maureen Lage introduced a new teaching method while giving lessons at University of Miami, i.e., multimedia and World-Wide-Web were utilized to make students watch teaching videos at home and appointed work was finished by group cooperation in classroom. This teaching method was rudiment of the Flipped Classroom, but a related specific term was not given to such a teaching form at that time. In 2001, the situation that Massachusetts Institute of Technology developed 'open courseware projects' drives researches on open educational resources and laid a foundation for application of the Flipped Classroom mode. In 2004, the American people Salam Khan made videos about coaching materials and uploaded them to website, which was popular among learners. Later, he founded Khan Research Institution and uploaded more learning materials to network, driving rapid development of the Flipped Classroom. In 2007, Jon Bergmann and Aaron Sams, two chemistry teachers at America high schools, uploaded PowerPoint they had made to network and asked students to learn after class and finish homework in classroom. In doing so, they achieved unexpected teaching effect. Since then, the Flipped Classroom mode has been popularized at all American colleges and universities generally. In 2011, New York Times and Global Times published articles about the Flipped Classroom and called it a great reform of classroom teaching modes.

Based on systematic researches on the Flipped Classroom, Jukui Middle School (Jiangjin District, Chongqing City, China) built a teaching video platform and a learning management platform, configured tablet personal computers for students, implemented the Flipped Classroom mode formally and guided students to develop personalized study in the autumn of 2011. Currently, Chinese researches on the Flipped Classroom still stay at an initial stage. From 2011 to 2012, there were only a few research achievements on the Flipped Classroom in CNKI database, i.e., only 19 
articles. Since 2012, the number of literatures studying the Flipped Classroom has increased obviously, which indicates that the Flipped Classroom draws more and more attention from Chinese educational world.

\section{Teaching design about the Flipped Classroom mode}

(I) Developing activities before class

1. Making teaching videos. When teachers make videos for students, they should pay attention to the following aspects: it is essential to ensure videos they make accord with requirements of teaching content; videos may adopt the method that combines blackboard writing with sound and time length should be kept within 10 minutes as much as possible; to ensure videos can guide students, teachers should design about elements, such as highlight themes, key points and interaction etc.

2. Setting exercises before class. When teachers set exercises before class for students, they should learn and master students' cognitive structure and design difficult and quantity of exercises reasonably. In addition to ensuring moderate difficult, the number of exercises should not be too large. Teachers should make students feel challenges from exercises, which can contribute to arousing their interest in study.

3. Students watch teaching videos. In this process, students may start with improving learning efficiency and control watching time and rhythm. In another word, they may speed or speed reverse videos or suspend them for thinking and record achievements after watching videos in order that they can communicate and share with other classmates.

4. Students' exercises before class. After watching videos, students need finish exercises that teachers have arranged in advanced to consolidate the knowledge they have learned. In this process, students may think about problems they find. In case such problems cannot be solved, they should write them down in order that they can solve it by communication and interaction at next step.

5. Using the media for mutual communication. In this process, students may have the help of media tools like chat room and message board to communicate with other students, share their achievements in learning, discuss problems they have met in exercises and solve such problems mutually. For the problems that they cannot solve via cooperation, they may tell teachers via remote feedback. At this moment, teachers may help students solve puzzling problems.

Since students need finish all links of pre-class activities, parents should supervise students when they learn and coach them when students face with problems to improve efficiency. For students with pool self-control ability, parents need coordinate with teachers for formulate some measures to drive them to learn knowledge better and enhance their comprehension about their children's study in this process.

(II) Organizing classroom activities

Constructivism theory points out that the process in which learners obtain knowledge is the process where meaning construction is realized by interpersonal communication and cooperative activities under some scenes. For this, when teachers design classroom activities for students, they should use four basic elements of the constructivism theory as bases, give full play to students' subjective initiative and make them carry out practical application of the knowledge they have learned in order to realize the goal knowledge internalization.

1. Teachers and students decide problems that will be explored. Teachers may ask students some questions according to difficult and key points in teaching content, and students may ask questions about puzzles and difficulty that they fail to solve when they watch videos and do exercises. Then, questions in the two aspects may be synthesized for classroom exploration.

2. Students solve problems independently. In teaching activity design of the Flipped Classroom mode, teachers ought to start with cultivating students' independent learning ability and let students choose exploration subjects independently and finish the work by themselves. In this way, they may enable students to internalize the knowledge they have learned in classroom gradually and then construct their knowledge structural system. 
3. Organizing exploration activities. Teachers may combine with students' individual features to group them. The number of members in each group may be controlled to be 3-5 and the group leader is elected by group members. Then, teachers distribute exploration subjects to each learning group. It is required that all members in the group should take part in exploration activities actively. Members in a group may finish learning goals by communication and cooperation jointly. In this process, teachers may check learning situations of each group randomly and give appropriate guidance.

4. Showing students' achievements. After finishing exploration activities, achievements of each group and all group members may be shown in classroom by speech, demonstration or small matches specifically. Meanwhile, groups may communicate with one another and share their own learning achievements.

5. Teaching evaluation and feedback. In the Flipped Classroom mode, evaluation members not only contain teachers but also involve students and their patents; and evaluation content contains exercise performance, performance of students when they solve problems independently in classroom, their behaviors in exploration activities and achievement exhibition etc. Teachers may design exploration problems of the next step in accordance with feedback information.

\section{Application of the Flipped Classroom mode}

The Flipped Classroom mode is a major reform of classroom teaching. To apply it to educational and teaching fields of China, we must analyze its application advantages and disadvantages carefully and make feasible countermeasures based on this.

(I) Application advantages of the Flipped Classroom mode

1. It helps teachers arouse students learning interest. The Flipped Classroom mode builds relatively relaxing learning environment, integrates teaching resources like teaching videos and situation materials, changes students' pre-class learning content from monotonous and boring characters to visual and vivid videos and has ability to arouse students' learning enthusiasm. The situation that teachers use network teaching platform to organize teaching activities really reflects the teaching concept that students are subjects and teachers play a leading role and makes students make progress in learning in mutual cooperation and mutual help.

2. It helps teachers cultivate students' independent learning ability. Students may use abundant teaching resources on Internet and combines with their own situations to control learning time, rhythm and depth reasonably and obtain personalized learning experience. When they meet learning difficulty, students may use network teaching platform to ask for help from teachers and their classmates. Meanwhile, parents may observe students' performance in independent learning and supervise students' learning situations. In doing so, interaction among students, parents and teachers may be realized. Thus, it can be found that the Flipped Classroom mode is a personalized learning strategy, which is helpful for cultivation of students' independent learning ability and improvement in students' learning effect.

3. It contributes to building harmonious relationship between teachers and students. In the Flipped Classroom mode, teachers guide students to construct knowledge hierarchy independently, following the students-centered teaching principle. In classroom, teachers endow students with equal right of speech, make students be able to express their own opinions and enable students to finish learning tasks in mutual cooperation. Teachers should capture dynamic states of students' inquiry learning in time, give appropriate guidance and become learning partners of students. This is helpful for construction of harmonious and interactive relationship between teachers and students. (II) Application disadvantages of the Flipped Classroom mode

(1) Short application and popularization time. The time when the Flipped Classroom mode is applied and popularized is not long, so researches on its related theories and practical application need be developed deeply. In foreign countries, it was in 2007 that the mode was applied for the first time. It was not popularized energetically at all colleges until 2011. China applied the mode at the end of 2011 for the first time. Recently, only several schools of China have introduced the Flipped Classroom mode. Besides, application of this mode still stays at its experimental stage. 
Problems appearing its application have not been solved appropriately. Additionally, some teaching resources are not comprehensive or sufficient.

(2) Network teaching video resources are limited. The Flipped Classroom mode need rely on network videos to realize knowledge instruction of teachers and students' knowledge conversion. Although China has established many high-quality curriculum websites and teaching video websites, network teaching video resources needed by the Flipped Classroom mode are rather limited.

(III) Countermeasures for the Flipped Classroom mode

As China pay more and more attention to educational informationization, good environment is created for application of the Flipped Classroom mode under the educational background that teaching modes and learning method innovation are advocated.

1. Improving comprehensive quality of teachers. The Flipped Classroom mode proposes high requirements for teachers' professional ability, so schools should enhance training for teachers and improve their comprehensive quality. Specifically, schools should organize teachers to learn experience in foreign teaching reform and invite teaching reform experts to give lectures regularly to strengthen teachers' cognition about the Flipped Classroom mode. Teachers should master skills making teaching videos, make teaching videos splendid and diversified, avoid monotonous explanation, highlight teaching key points and difficult points and increase text copies which are corresponding to videos. Moreover, teachers ought to master situations about students' independent learning, follow the principle 'teaching students in accordance with their aptitude' and correct their bad learning habits. Furthermore, teachers should formulate corresponding classroom teaching strategies according to subject features, arrange research-style learning activities reasonably, build harmonious, friendly and democratic classroom discussion atmosphere and arouse students' enthusiasm for discussion.

2. Improving students' information literacy. Under the Flipped Classroom mode, students must have good self-study ability and information literacy and can look up related learning materials independently after watching teaching videos and then finish learning tasks with teachers and classmates in classroom. For this, teachers should attach importantance to improvement in students' information literacy and make students have some network application ability and capacity to operate computer.

3. Carrying out innovation for teaching evaluation mode. Under the Flipped Classroom mode, it is essential to improve traditional teaching evaluation methods and make teaching evaluation not only cover assessment on several kinds of ability, such as students' cooperative ability, self-study ability, organizing ability and ability of expression but also attaches importance to evaluation on students' emotion, attitudes and value. Besides, teaching evaluation should be finished by learning partners, students themselves, teachers and parents.

\section{Conclusion:}

In short, the Flipped Classroom mode is a new teaching mode which reflects the 'students-centered' principle, reverses the order in which learning content is spread and internalized and makes students be able to allocate cognitive resources so as to obtain good learning effect. However, domestic researches on the Flipped Classroom mode still stay at an initial stage. Therefore, in teaching application, educators need integrate advanced teaching concepts and techniques effectively, drive teaching reform and provide personalized learning environment for students.

\section{Acknowledgments}

This thesis is a research project of educational and teaching reform carried by Ankang Unviersity, named Research on Application of Flipped Classroom Mode to Teaching Reform about Specialized Courses of Primary School Education (project No.: Jg07226). 


\section{References}

[1] Zhao Xinglong. Knowledge internalization process and teaching mode design in Flipped Classroom [J]. Modern Distance Education Research, 2014(3).

[2] Lai Yan, Hou Yongxian, Zhao Jiaojiao. The first exploration on Flipped Classroom: application of micro classroom to mathematics at primary schools [J]. Information Technology Education of Middle and Primary School, 2014(3).

[3] Li Cou, Liu Ganhong. SWOT analysis of application of Flipped Classroom teaching mode [J]. Chinese Educational Technology Equipment, 2013(1).

[4] Lu Jia, Tang Shuyan. Research on application of 'Flipped Classroom' to practical teaching of audio-visual language editing [J]. Young Litterateurs, 2014(3).

[5] Ma Xiulin, Zhao Guoqing, Wu Tong. Empirical study on Flipped Classroom teaching in colleges’ information technology public courses [J]. Remote Education Magazine, 2013(2).

[6] Wang Xiaodong, Zhang Chen. Research on application of 'Flipped Classroom' to college teaching - Take English course of educational technology major as an example [J]. Modern Educational technology, 2013(8).

[7] Zhu Weili. Teaching design on document information retrieval course based on Flipped Classroom [J]. Library Magazine, 2013(4). 